\title{
Thelytokous parthenogenesis and its consequences on inbreeding in an ant
}

\author{
M Pearcy, O Hardy and S Aron \\ Behavioral and Evolutionary Ecology, Université Libre de Bruxelles, Brussels, Belgium
}

\begin{abstract}
Thelytokous parthenogenesis, that is, the production of diploid daughters from unfertilized eggs, may involve various cytological mechanisms, each having a different impact on the genetic structure of populations. Here, we determined the cytological mechanism of thelytokous parthenogenesis and its impact on inbreeding in the ant Cataglyphis cursor, a species where queens use both sexual and asexual reproduction to produce, respectively, workers and new queens. It has been suggested that thelytokous parthenogenesis in $C$. cursor might have been selected for to face high queen mortality and, originally, to allow workers to replace the queen when she passes away. We first determined the mode of thelytokous parthenogenesis by comparing the rate of transition to homozygosity at four highly polymorphic loci to expectations under the different modes of parthenogenesis. Our data show that thelytoky is
\end{abstract}

achieved through automictic parthenogenesis with central fusion. We then estimated the proportion of colonies headed by worker-produced queens in a natural population. We designed a model linking the observed homozygosity in queens to the proportion of queens produced by workers, based on the assumption that (i) parthenogenesis is automictic with central fusion and (ii) queen lineage is asexually produced, resulting in an increase of the inbreeding over generations, whereas workers are sexually produced and therefore not inbred. Our results indicate that more than $60 \%$ of the colonies should be headed by a worker-produced queen, suggesting that queen's lifespan is low in this species.

Heredity (2006) 96, 377-382. doi:10.1038/sj.hdy.6800813; published online 22 March 2006

Keywords: ants; parthenogenesis; Cataglyphis cursor, social organization; inbreeding; queen turnover

\section{Introduction}

Hymenoptera (ants, bees and wasps) are characterized by a haplodiploid sex-determining system, whereby males arise from unfertilized eggs through arrhenotokous parthenogenesis and are haploid, whereas females develop from fertilized eggs and are diploid. In a few species, however, unmated females may produce diploid daughters from unfertilized eggs through thelytokous parthenogenesis. Thelytokous parthenogenesis is uncommon in the animal kingdom and has only been reported in about 1500 species (White, 1984). In Hymenoptera, thelytoky has been documented in some taxa, including Cynipidae, Tenthredinidae, Aphelinidae, Ichneumonidae, Apidae and Formicidae (reviewed in Slobodchikoff and Daly, 1971; Suomalainen et al, 1987).

On a cytological basis, thelytokous parthenogenesis can be divided into two main types. In apomictic (or ameiotic) parthenogenesis, there is no recombination of alleles and the offspring are 'true clones' of the mother. In automictic (or meiotic) parthenogenesis, the first stages of meiosis are similar to the ones in sexual reproduction, but fusion occurs between two nuclei originating from the same individual. Gene recombination can occur. Different mechanisms are known to

Correspondence: M Pearcy, Behavioral and Evolutionary Ecology, CP 160/ 12, Université Libre de Bruxelles, 50, av. FD Roosevelt, B-1050 Brussels, Belgium.E-mail: mpearcy@ulb.ac.be

Received 28 June 2005; accepted 17 February 2006; published online 22 March 2006 restore the ploidy level in individuals developing from automictic parthenogenesis (see Figure 1): terminal fusion, central fusion, gamete duplication and several alternative mechanisms referred to as 'random fusion'. The majority of parthenogens for which the cytological mechanism has been investigated in animals are automictic (Cook, 1993).

The mode of thelytokous parthenogenesis is important to assess in population genetics studies because each mode has a different impact on inbreeding. In automictic parthenogenesis with terminal fusion (Figure 1a), the offspring is completely homozygous, except when recombination occurs between the centromere and the locus. When the locus is far enough from the centromere, crossing over occurs and one may consider that alleles segregate independently. In this situation, the probability for an heterozygous locus of turning homozygous equals the mathematical probability of picking two identical alleles ( $a$ or $b$ ) among two pairs of alleles ( $a a$ and $b b$ ) without replacement, that is, $1 / 3$. Hence, each heterozygous locus has a probability ranging from 1/3 (far from centromere) to 1 (close to centromere) of becoming homozygous (Table 1). In automictic parthenogenesis with central fusion (Figure 1b), the offspring is genetically similar to the mother, except when there is recombination. With a similar reasoning, each heterozygous locus has a probability ranging from 0 (close to centromere) to $1 / 3$ (far from centromere) of becoming homozygous. In automictic parthenogenesis with 'random fusion' (Figure 1c), one may consider that all four chromatids segregate independently, and each hetero- 
378

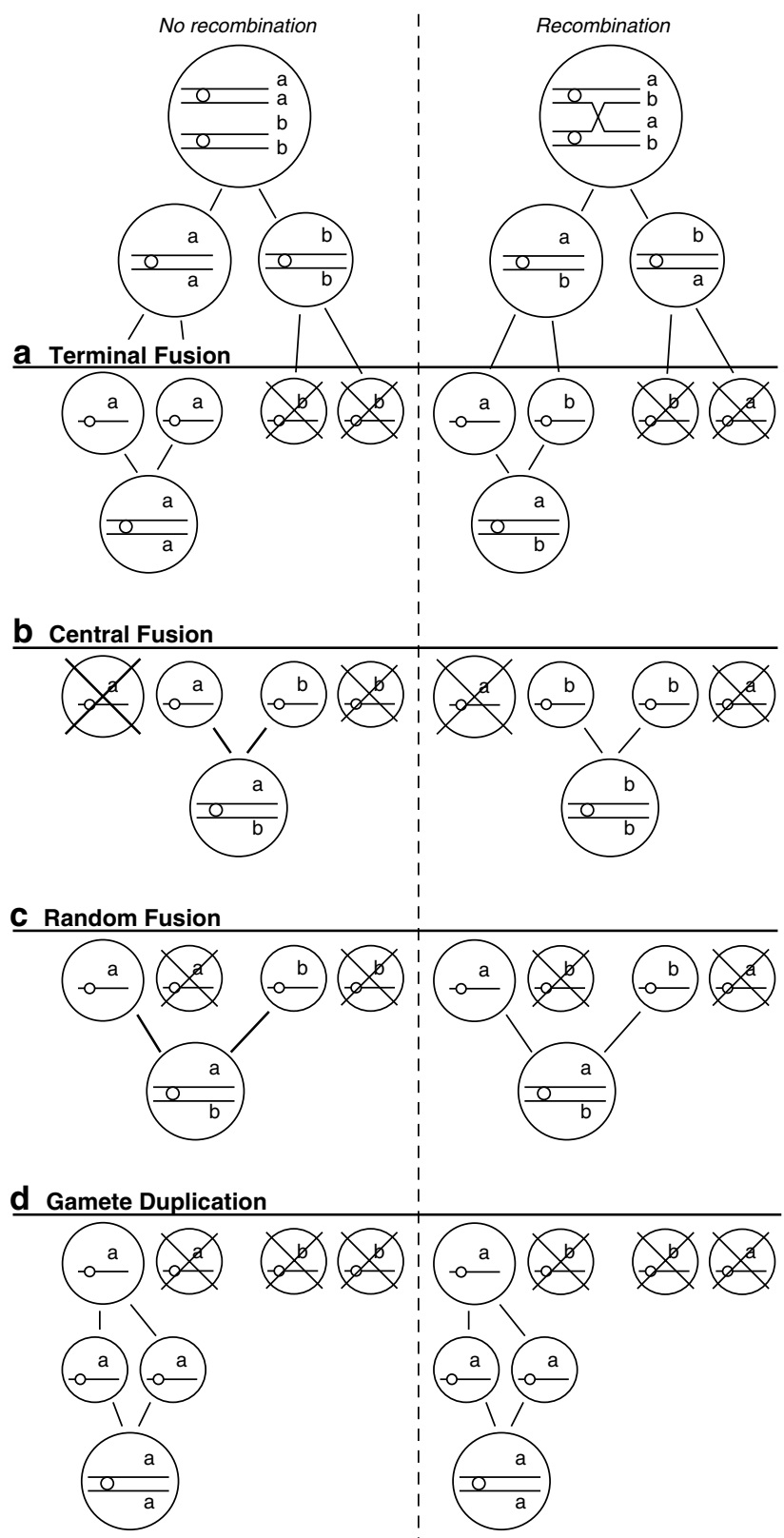

Figure 1 Different cytological mechanisms during meiosis leading to automictic parthenogenesis and their impact on inbreeding at a locus when a crossing over between the locus and the centromere occurs or not (modified from Suomalainen et al, 1987). Circles represent nuclei. Horizontal lines represent chromatids, with small circles showing the location of the centromere and letters representing alleles at a given locus. The parent is heterozygous (ab) and parthenogenesis causes inbreeding when its progeny becomes homozygote (aa or bb).

zygous locus has a probability of $1 / 3$ of becoming homozygous, independent of its position on the chromosome. In automictic parthenogenesis with gamete duplication (Figure 1d), the offspring is homozygous for all loci. Eventually, in apomictic parthenogenesis, there is no recombination and no increase in homozygosity. Table 1 summarizes how the different modes of parthenogenesis affect inbreeding.

In social Hymenoptera, it has been shown that thelytoky of Apis mellifera capensis workers is controlled by a single locus (Lattorff et al, 2005). Cytological analysis
Table 1 Range of the expected rates of transition to homozygosity of a heterozygous locus $(r)$ for different modes of parthenogenesis according to the distance to the centromere

Mode of parthenogenesis

Locus position

Close to centromere Far from centromere (no recombination) (many crossing over)

\begin{tabular}{lll}
\hline Terminal fusion & 1.00 & 0.33 \\
Central fusion & 0.00 & 0.33 \\
Random fusion & 0.33 & 0.33 \\
Gamete duplication & 1.00 & 1.00 \\
Apomictic & 0.00 & 0.00 \\
\hline
\end{tabular}

indicated that diploidization results from automictic parthenogenesis with central fusion, that is, the fusion of two of the four meiotic products that have a central position on the spindles and that were separated at the first meiotic division, whereas the two terminal nuclei degenerate (Verma and Ruttner, 1983; Baudry et al, 2004). In ants, thelytokous parthenogenesis has been unambiguously demonstrated in six phylogenetically distant species only: Cataglyphis cursor (Cagniant, 1973), Pristomyrmex pungens (Itow et al, 1984), Cerapachys biroi (Tsuji and Yamauchi, 1995), Platythyrea punctata (Heinze and Hölldobler, 1995; Schilder et al, 1999), Messor capitatus (Grasso et al, 2000) and Wasmannia auropunctata (Fournier et al, 2005). In the ponerine ant P. punctata, Schilder et al (1999) showed that all individuals belonging to the same population are almost genetically identical to each other, suggesting that thelytokous parthenogenesis is apomictic. In the five other species, the mode of parthenogenesis underlying thelytoky remains unknown.

In this paper, we investigated the cytological mechanism of thelytokous parthenogenesis and its impact on inbreeding in the ant C. cursor. In this species, workers are able to produce females (workers and queens) parthenogenetically in colonies that have lost the mother queen (Cagniant, 1973). It has been suggested that this ability would allow workers to replace the queen (Lenoir and Cagniant, 1986), but this hypothesis has not been investigated so far. Recently, it has been shown that not only unmated workers but also mated queens of C. cursor can use thelytokous parthenogenesis (Pearcy et al, 2004a). While workers are produced by normal sexual reproduction from fertilized eggs, new queens (gynes) are almost exclusively produced by parthenogenesis. Data suggested that thelytoky proceeded by central fusion, but this hypothesis was not unambiguously demonstrated.

Here, we aimed to solve two major issues raised by these findings. First, we determined the mode of parthenogenesis of C. cursor. By using genetic markers, we compared the pedigree of the queen and her thelytokous daughters to estimate the rates of transition to homozygosity at each locus, and compared these values to the expected rates of homozygosity under different modes of parthenogenesis. Second, we estimated the proportion of colonies headed by a replacement queen produced by the workers in a natural population. This was achieved by comparing the observed level of inbreeding of queens with the estimated rate of transitions to homozygosity for each locus, using expectations for a population at equilibrium. 


\section{Materials and methods}

\section{Field collection and sampling}

C. cursor is found in the stretches of steppe and Mediterranean forest up to dry forest, and is discontinuously distributed from central Spain to Mongolia (Agosti, 1990). Nests of C. cursor possess a single entrance and usually one vertical gallery leading to rooms located up to $1 \mathrm{~m}$ deep, sometimes right above the water level. This species is characterized by the absence of overwintering brood (Cagniant, 1976). Queens lay eggs from early March to early September. Adult sexuals of C. cursor emerge in mid-May; mating occurs in the nest in early June, and is followed 1-3 weeks later by colony budding (Lenoir et al, 1988). Transfer of workers and brood between the mother and daughter nests can last for some more weeks, after which colonies remain isolated from each other.

Thirty-five nests of C. cursor were excavated in the end of April/early May 2001 at St-Hyppolite (southern France; $42.82^{\circ}$ North, $2.99^{\circ}$ East), before the emergence of the first sexuals. Colonies whose entrance were located too close (distance $<1 \mathrm{~m}$ ) from each other were not collected so as to prevent mixing individuals from different nests. Adults (queens and workers) as well as brood at various stages (eggs, larvae and both worker and sexual pupae) were collected and brought into the laboratory. A sample of workers from each nest was immediately stored at $-80^{\circ} \mathrm{C}$ for subsequent genetic analyses. Colonies were housed in artificial nests. They were maintained under laboratory conditions $\left(26 \pm 2^{\circ} \mathrm{C}\right.$ and 12:12 h L:D) and were fed on cockroaches, sugar water and grape. Colonies were censused twice a week and all sexuals emerging from the pupae were collected and deep-frozen.

\section{DNA extraction and microsatellite analysis}

Four microsatellite loci (Ccur-46, Ccur-11, Ccur-58 and Ccur-63b; Pearcy et al, 2004b) exhibiting, respectively, 11, 13,14 and 11 alleles were used to determine the genotype of individuals. Individual ant DNA was extracted by homogenization in a digestive solution $(100 \mathrm{mM} \mathrm{NaCl}$, $50 \mathrm{mM}$ Tris, $1 \mathrm{mM}$ EDTA, $0.5 \%$ SDS and $200 \mu \mathrm{g} / \mathrm{ml}$ proteinase $\mathrm{K}$ (BIOGENE)) and incubated for $2 \mathrm{~h}$ at $55^{\circ} \mathrm{C}$. Genomic DNA was purified by phenol/chloroform and precipitated with ethanol following standard protocols, and then suspended in $100 \mu \mathrm{l}$. Amplifications were carried out in a $10 \mu \mathrm{l}$ volume using the standard $10 \times$ Buffer and Taq from QIAGEN Polymerase kit (Pearcy et al, 2004b). Amplified fluorescent fragments were visualized using an automated ABI Prism 310 sequencer.

\section{Data analysis}

Allele segregation and mode of parthenogenesis: From the 35 nests sampled, 10 produced gynes and the number of gynes per colony was usually small $(1-17, n=56$ in total). To assess allele segregation under thelytokous parthenogenesis, we determined for each locus the proportion of homozygous gynes produced by heterozygous mothers, $R$. Thus, $R$ corresponds to the generational rate of transition to homozygosity and quantifies how parthenogenesis increases the inbreeding coefficient. Under parthenogenesis with terminal or central fusion, $R$ is expected to vary among loci according to their position relative to the centromere (Table 1).

We compared $R$ values with theoretical expectations $(r)$ for five different modes of thelytokous parthenogenesis (as a convention, we use lower case letters to denote parameters and capital letters for the corresponding estimators): apomixis $(r=0)$, automixis with gamete duplication $(r=1)$, terminal fusion $(r=1 / 3-1)$, fusion of two products of the first meiotic division, here referred as random fusion $(r=1 / 3)$ and central fusion $(r=0-1 / 3)$. $\chi^{2}$ tests were used to determine which mode of parthenogenesis was consistent with the observed rate of transition to homozygosity for each locus. When $r$ is comprised within a range of values, the value closest to the observed $R$ was used for the test. For the two exclusive modes of parthenogenesis where no or all offspring are expected to be homozygous (ie, apomixis or automixis with gamete duplication, respectively), $P$-values were considered equal to 0 when at least one individual was not consistent with these expectations for a given locus.

Inbreeding coefficient: In all, $12-30$ workers $(X \pm S D=$ $15.3 \pm 5.8 ; n=535)$ and the queen $(n=33$; two queens died before genetic analyses) were typed from each nest. The individual inbreeding (the probability that two alleles within individuals are identical by descent) was estimated for workers $\left(F_{\mathrm{w}}\right)$ and for queens $\left(F_{\mathrm{q}}\right)$ by the program SPAGeDi (Hardy and Vekemans, 2002) using J Nason's estimator (Loiselle et al, 1995).

Proportion of colonies headed by a worker-produced queen: The proportion of colonies headed by a replacement queen produced by the workers was estimated from a model predicting the inbreeding of queens $\left(f_{\mathrm{q}}\right)$ from the generational rate of transition to homozygosity $(r)$ and the proportion of workerproduced queens $(w)$. The model assumes that queens are produced by automictic parthenogenesis with central fusion, and that workers are produced sexually and are not inbred. These assumptions hold for C. cursor (see Results).

At a given locus, the probability of identity-by-descent for the two alleles of a parthenogenetically produced queen equals 1 if her mother carried alleles already identical by descent, and $r$ otherwise. Hence, the inbreeding of a queen at the next generation $\left(f_{\mathrm{q}}\right)$ can be expressed according to the inbreeding of its parents $(f)$ :

$$
f_{\mathrm{q}}^{\prime}=f+(1-f) r
$$

Considering that the mother can be a worker $(f=0)$ with probability $w$, or a queen $\left(f=f_{\mathrm{q}}\right)$ with probability $1-w$, the average inbreeding of daughter queens is:

$$
f_{\mathrm{q}}^{\prime}=(1-w) \cdot\left(f_{\mathrm{q}}+\left(1-f_{\mathrm{q}}\right) r\right)+w \cdot r
$$

At equilibrium, when the average inbreeding of queens does not change between generations, $f_{q}=f_{q}$, so that

$$
f_{\mathrm{q}}=\frac{r}{r+w(1-r)}
$$

Thus, the equilibrium inbreeding of queens ranges between $r$ (all produced by workers) and 1 (all produced by queens). By inverting Equation (1) and replacing 
parameters by their respective locus-specific estimators, one can get an estimator of the proportion of workerproduced queens $(W)$ :

$$
W=\frac{\left(1-F_{\mathrm{q}}\right) R}{(1-R) F_{\mathrm{q}}}
$$

Since the mode of parthenogenesis is assumed to be automixis with central fusion, we restricted the range of $R$-values between 0 and $1 / 3$ (estimates above $1 / 3$ were reduced to $1 / 3$ ). A previous study (Pearcy et al, 2004a) showed that the proportion of queens arising from sexual reproduction is very low (about 4\%). Consequently, sexually produced queens were not considered in the model.

\section{Results}

\section{Mode of parthenogenesis}

The proportion of homozygous gynes produced by heterozygous mothers $(R)$ ranged between 0.06 and 0.44 , depending on the locus (Table 2). These values were significantly different for at least two loci from those expected under apomixis, automixis with terminal fusion, gamete duplication or random fusion. By contrast, none were different from the values expected under automictic parthenogenesis with central fusion, showing that this cytological mechanism is involved in the production of thelytokous daughters by queens of C. cursor.

\section{Inbreeding and proportion of worker-produced queens} The inbreeding coefficient at each locus was not significantly different from 0 for workers. By contrast, it ranged from 0.02 to 0.42 for queens and was significant for three of the four loci analyzed (Table 3).

Applying Equation (2), our data show that more than $60 \%$ of the colonies in the study population were headed by a worker-produced queen. Locus-specific estimates of $W$ varied from 0.63 to 0.87 for the three loci Ccur-46, Ccur-58 and Ccur-63b (Table 3). Locus Ccur-11 gives $W>1$ because $R>F_{\mathrm{q}}$. The low rate of transition to homozygosity $(R)$ at Ccur-11 suggests that this locus is close to the centromere, making this locus not very informative concerning the impact of parthenogenesis on inbreeding. The fact that our estimates of $W$ for Ccur-11 are out of the expected range stems from the high variance associated with the low value of $R$ (Table 2).
Table 3 Observed inbreeding coefficients in workers $(n=514)$ and queens $(n=33)$, and estimation of the rate of worker-produced queens

\begin{tabular}{lrccc}
\hline Locus & \multicolumn{1}{c}{$\mathrm{F}_{w}$} & $\mathrm{~F}_{q}$ & $\mathrm{R}$ & $\mathrm{W}$ \\
\hline Ccur-11 & 0.01 & 0.02 & 0.06 & $>1$ \\
Ccur-46 & -0.02 & $0.37^{\mathrm{a}}$ & 0.33 & 0.87 \\
Ccur-58 & 0.03 & $0.42^{\mathrm{a}}$ & 0.33 & 0.70 \\
Ccur-63b & 0.02 & $0.25^{\mathrm{a}}$ & 0.17 & 0.63
\end{tabular}

$F_{\mathrm{w}}$ : inbreeding of workers. $F_{\mathrm{q}}$ : inbreeding of queens. $R$ : estimated rate of transition to homozygosity during parthenogenesis (bounded between 0 and $1 / 3$ in accordance with theoretical expectations for automictic parthenogenesis with central fusion). $W$ : estimated rate of worker-produced queens from $F_{\mathrm{q}}$ and $R$ when applying Equation (2)

anbreeding significantly $>0 . W>1$ means that an estimate above 1 has been obtained.

\section{Discussion}

Our results show that the cytological mechanism responsible for thelytokous parthenogenesis in queens of the ant C. cursor is automictic parthenogenesis with central fusion. Whether the same mechanism underlies the parthenogenetic production of females by workers remains to be verified, but the hypothesis that parthenogenesis evolved once in this species seems more parsimonious. Automictic parthenogenesis with central fusion is also involved in the production of females by unmated workers in the cape honeybee Apis mellifera capensis (Verma and Ruttner, 1983). Interestingly, Baudry et al (2004) reported an average reduction of heterozygosity per generation and per individual $(R)$ of about 0.19 , a value well in the range of $0.06-0.33$ (mean: 0.21) found in this study. By contrast with C. cursor, Schilder et al (1999) reported that reproduction in parthenogenetic populations of the ant Platythyrea punctata is apomictic. This suggests that different modes of thelytokous parthenogenesis evolved independently in different lineages of the Formicidae.

Automictic parthenogenesis results in an increased level of homozygosity, which may cause inbreeding depression. The main mechanism responsible for inbreeding depression depends on the genetic load of recessive deleterious alleles (partial dominance hypothesis; Charlesworth and Charlesworth, 1999; Roff, 2002). Anything that would reduce the genetic load would therefore also reduce inbreeding depression, which results in two predictions. First, prolonged inbreeding

Table 2 Observed rates of transition to homozygosity during parthenogenesis and consistency with different modes of parthenogenesis

\begin{tabular}{|c|c|c|c|c|c|c|c|c|}
\hline \multirow[t]{2}{*}{ Locus } & \multirow[t]{2}{*}{$N t$} & \multirow[t]{2}{*}{ No } & \multirow[t]{2}{*}{$\mathrm{R}(95 \% \mathrm{CI})$} & \multicolumn{4}{|c|}{ Automyxy } & \multirow{2}{*}{$\begin{array}{c}\text { Apomyxy } \\
(\mathrm{r}=0)\end{array}$} \\
\hline & & & & $\begin{array}{l}\text { Gamete duplication } \\
\qquad(\mathrm{r}=1)\end{array}$ & $\begin{array}{l}\text { Terminal fusion } \\
\quad(\mathrm{r}=1 / 3-1)\end{array}$ & $\begin{array}{l}\text { Central fusion } \\
(\mathrm{r}=0-1 / 3)\end{array}$ & $\begin{array}{l}\text { Random fusion } \\
\quad(\mathrm{r}=1 / 3)\end{array}$ & \\
\hline Ccur-11 & 53 & 3 & $0.06(0.02-0.15)$ & $* * *$ & $* * *$ & NS & $* * *$ & $* * *$ \\
\hline Ccur-46 & 46 & 20 & $0.44(0.29-0.60)$ & $* * *$ & NS & NS & NS & $* * *$ \\
\hline Ccur-58 & 47 & 16 & $0.34(0.21-0.50)$ & $* * *$ & NS & NS & NS & $* * *$ \\
\hline Ccur-63b & 41 & 7 & $0.17(0.08-0.34)$ & $* * *$ & $* * *$ & NS & $* * *$ & $* * *$ \\
\hline
\end{tabular}

$N t$ : number of offspring from heterozygous mother; No: number of transitions to homozygosity; R: observed rate of transition to homozygosity; $r$ : expected rate (or range of rates) of transition to homozygosity (see Table 1).

$\chi^{2}$ tests of consistency of $R$ values with $r$ : NS: not significant; ${ }^{* * *}$ highly significant $(P<0.001)$. When $r$ is a range, the test was performed considering the $r$ closest to $R$ within the range. 
should lead to purging of the genetic load due to increased exposure of deleterious mutations in homozygotes (Lande and Schemske, 1985; Charlesworth and Charlesworth, 1987; Waller, 1993). Second, in species with haploid-male sex determinism such as Hymenoptera, deleterious mutations are regularly exposed to selection in males. Selection therefore acts as a powerful purge for deleterious alleles, which explains why Hymenoptera should be less prone to inbreeding depression (Brückner, 1978; Smith and Shaw, 1980; Crozier, 1985; Werren, 1993; Saito et al, 2000). Both hypotheses suggest that the genetic load associated with inbreeding should be reduced in the ant Cataglyphis cursor, where queens are produced parthenogenetically and show a high level of homozygosity. Moreover, it has been suggested that queens of C. cursor are less subject to inbreeding depression than most ant species because they found new colonies by budding. The absence of mating flight and the ability to start a new colony with the help of adult workers should indeed lower the selective pressure on queens (Pearcy et al, 2004a). Another possible genetic consequence of increased homozygosity due to automictic parthenogenesis is the production of diploid males. Diploid males develop from eggs that are homozygous at the sex-determining locus (or loci) and are functionally sterile, so that their production generates a genetic load to the colony (Crozier, 1977; Cook, 1993). However, adult diploid males have not been found in a large subsample of C. cursor males (Pearcy et al, in preparation).

In C. cursor, two nonmutually exclusive processes may counteract genetic homogenization induced by automictic parthenogenesis. First, previous studies showed that $3.6 \%$ of gynes are produced by sexual reproduction (Pearcy et al, 2004a). This proportion seems, however, too small to account on its own for the level of heterozygosity (range: 0.57-0.94) observed in queens. Second, workers can produce gynes in the absence of the mother queen (Cagniant, 1979). As workers arise from sexual reproduction, their contribution to the next generation should decrease the level of inbreeding. Consistently, our results indicate that inbreeding coefficient for workers does not differ from zero.

Our genetic analyses also show that more than $60 \%$ of the colonies are headed by queens produced by workers in the study population. Our estimate of workerproduced queens may have been slightly overestimated, because females arising from sexual reproduction of mother queens are genetically similar to (and are therefore counted as) those arising from worker reproduction. However, as mentioned above, females arising from sexual reproduction of mother queens are rare (Pearcy et al, 2004a) and cannot substantially bias our estimates.

The high proportion of colonies headed by workerproduced queens found in this study strongly suggests that queen replacement is a common phenomenon in the ant C. cursor. In spring, freshly inseminated queens of this species may either leave the nest with a group of workers (colony budding) or stay in the nest and replace the mother queen (queen replacement). Both options result in the same colony genetic architecture. However, production of eggs developing into sexuals is restricted to a short period of time in early spring, and adult sexuals emerge within 40 days (Cagniant, 1979). Therefore, replacement of a mother queen by one of her own thelytokous daughters may occur only if she dies in the meantime, making colony budding a more likely explanation for worker-produced queens in early spring. Conversely, if the mother queen dies outside of the period of sexual production, workers will start to produce sexual offspring from the next spring, leading to queen replacement. Variations over time in colony kin structure due to the replacement of old queen(s) by newly inseminated ones (ie, queen turnover) has been documented in several ant species (eg, Evans, 1996; Goodisman and Ross, 1999; André et al, 2001; reviewed in Heinze and Keller, 2000). However, queen turnover in thelytokous ant species has received little attention. To our knowledge, our study allows a first estimation of the rate of queen replacement by worker-produced queens in a natural population of a thelytokous ant.

In C. cursor, thelytokous parthenogenesis might have been selected for to face high queen mortality and replace the queen when she passes away (Lenoir and Cagniant, 1986). Keller and Genoud (1997) emphasized the close association between queen lifespan and (i) the colony kin structure and (ii) the mode of colony foundation in ants. They showed that the lifespan of queens is greater in monogynous than in polygynous species, and greater in independent than in dependent founding species. In most ants, monogyny is associated with independent colony founding, whereas polygyny is associated with dependent colony founding. Colonies of C. cursor do not fit with this general pattern: they are monogynous and foundation proceeds by budding. There is thus no prediction for queen lifespan in this species. Queen life expectancy remains unknown in the genus Cataglyphis, both under natural and laboratory conditions. As for workers, lifespan has been reported in a few species to be extremely low. For instance, foragers of $C$. bicolor reportedly live on average 6.1 days (Schmid-Hempel and Schmid-Hempel, 1984). Such a short life expectancy of worker foragers also occurs in C. cursor (Lenoir, personal communication). Since workers of $C$. cursor reproduce in queenless colonies only (Cagniant, 1980), the high proportion of colonies headed by a worker-produced queen found here suggests that the lifespan of queens should be relatively short in this species. In their study, Keller and Genoud (1997) also did not consider ant species where workers can produce females parthenogenetically, allowing queen replacement by workers. Whether this ability is associated with a short queen life expectancy remains unknown.

\section{Acknowledgements}

We thank E Baudry, M Chapuisat, C Doums and two anonymous referees for their useful suggestions and comments on the manuscript. We also thank L Brazier, S Chameron, L de Menten, C Tirard, P Van den Hove and $B$ Viginier for taking part in sample collection, and D Fournier, B Viginier, M Richard for their assistance while genotyping. This work was supported by grants from the Belgian Fond National de la Recherche Scientifique - FNRS (SA and $\mathrm{OH}$ ) and the Fonds pour la Recherche dans l'Industrie et l'Agriculture - FRIA (MP). 


\section{References}

Agosti D (1990). Review and reclassification of Cataglyphis (Hymenoptera Formicidae). J Nat Hist 24: 1457-1505.

André JB, Peeters C, Doums C (2001). Serial polygyny and colony genetic structure in the monogynous queenless ant Diacamma cyaneiventre. Behav Ecol Sociobiol 50: 72-80.

Baudry E, Kryger P, Allsopp MH, Koeniger N, Vautrin D, Mougel $\mathrm{F}$ et al (2004). Whole-genome scan in thelytokous laying workers of the Cape honeybee (Apis mellifera capensis): central fusion, reduced recombination rates, and centromere mapping using half-tetrad analysis. Genetics 167: 243-252.

Brückner D (1978). Why are there inbreeding effects in haplodiploid systems? Evolution 32: 456-458.

Cagniant H (1973). Apparition d'ouvrières a partir d'œufs pondus par des ouvrières chez la fourmi Cataglyphis cursor Fonscolombe (Hymenopteres: Formicidae). CR Acad Sci D Sci Nat 277: 2197-2198.

Cagniant H (1976). Distribution, écologie et nid de la fourmi Cataglyphis cursor Fonscolombe. Vie Milieu 26: 265-276.

Cagniant H (1979). La parthénogénese thélytoque et arrhénotoque chez la fourmi Cataglyphis cursor Fonsc. (Hym. Form.) Cycle biologique en élevage des colonies avec reine et des colonies sans reine. Insect Soc 26: 51-60.

Cagniant H (1980). Étude des stades larvaires de la lignée des ailes et de la lignée des ouvrières dans des colonies avec reine et des colonies sans reine chez la fourmi Cataglyphis cursor Fonsc. Bull Soc Hist Nat Toulouse 116: 192-206.

Charlesworth B, Charlesworth D (1999). The genetic basis of inbreeding depression. Genet Res 74: 329-340.

Charlesworth D, Charlesworth B (1987). Inbreeding depression and its evolutionary consequences. Annu Rev Ecol Syst 18: 237-268.

Cook JM (1993). Sex determination in the Hymenoptera: a review of models and evidence. Heredity 71: 421-435.

Crozier RH (1977). Evolutionary genetics of the Hymenoptera. Annu Rev Entomol 22: 263-288.

Crozier RH (1985). Adaptive consequences of male-haploidy. In: Helle W, Sabelis MW (eds) Spider Mites. Their Biology, Natural Enemies and Control. Elsevier: Amsterdam. Vol 1A, pp 201222 (Chapter 1.3.4)

Evans JD (1996). Queen longevity, queen adoption and posthumous indirect fitness in the facultatively polygynous ant Myrmica tahoensis. Behav Ecol Sociobiol 39: 275-284.

Fournier D, Estoup A, Orivel J, Foucaud J, Jourdan H, Le Breton $\mathrm{J}$ et al (2005). Clonal reproduction by males and females in the little fire ant. Nature 435: 1230-1234.

Goodisman MAD, Ross KG (1999). Queen recruitment in a multiple-queen population of the fire ant Solenopsis invicta. Behav Ecol 10: 428-435.

Grasso DAT, Wenseleers T, Mori A, Le Moli F, Billen J (2000). Thelytokous worker reproduction and lack of Wolbachia infection in the harvesting ant Messor capitatus. Ethol Ecol Evol 12: 309-314.

Hardy OJ, Vekemans X (2002). SPAGEDI: a versatile computer program to analyse spatial genetic structure at the individual or population levels. Mol Ecol Notes 2: 618-620.

Heinze J, Keller L (2000). Alternative reproductive strategies, a queen perspective in ants. Trends Ecol Evol 15: 508-512.

Heinze JB, Hölldobler B (1995). Thelytokous parthenogenesis and dominance hierarchies in the ponerine ant Plathytyrea punctata. Naturwissenschaften 82: 40-41.
Itow T, Kobayashi K, Kubota M, Ogata K, Imai HT, Crozier RH (1984). The reproductive cycle of the queenless ant Pristomyrmex pungens. Insect Soc 31: 87-102.

Keller L, Genoud M (1997). Extraordinary lifespans in ants: a test of evolutionary theories of ageing. Nature 389: 958-960.

Lande R, Schemske DW (1985). The evolution of self-fertilization and inbreeding depression in plants. I. Genetic models. Evolution 39: 24-40.

Lattorff HMG, Moritz RFA, Fuchs S (2005). A single locus determines thelytokous parthenogenesis of laying honeybee workers (Apis mellifera capensis). Heredity 94: 533-537.

Lenoir A, Cagniant H (1986). Role of worker thelytoky in colonies of the ant Cataglyphis cursor (Hymenoptera: Formicidae). Entomol Gen 11: 153-157.

Lenoir A, Quérard L, Pondicq N, Berton F (1988). Reproduction and dispersal of the ant Cataglyphis cursor (Hymenoptera Formicidae). Psyche 95: 21-44.

Loiselle BA, Sork VL, Nason J, Graham C (1995). Spatial genetic structure of a tropical understory shrub, Psychotria officinalis (Rubiaceae). Am J Bot 82: 1420-1425.

Pearcy M, Aron S, Doums C, Keller L (2004a). Conditional use of sex and parthenogenesis for worker and queen production in ants. Science 306: 1780-1783.

Pearcy M, Clémencet J, Chameron S, Aron S, Doums C (2004b). Characterization of nuclear DNA microsatellite markers in the ant Cataglyphis cursor. Mol Ecol Notes 4: 642-644.

Roff DA (2002). Inbreeding depression: tests of the overdominance and partial dominance hypotheses. Evolution 56: 768-775.

Saito Y, Sahari K, Mori K (2000). Inbreeding depression by recessive deleterious genes affecting female fecundity of a haplodiploid mite. J Evol Biol 13: 668-678.

Schilder K, Heinze J, Gross R, Hölldobler B (1999). Microsatellites reveal clonal structure of populations of the thelytokous ant Platythyrea punctata (F. Smith) (Hymenoptera; Formicidae). Mol Ecol 8: 1497-1507.

Schmid-Hempel P, Schmid-Hempel R (1984). Life duration and turnover of foragers in the ant Cataglyphis bicolor (Hymenoptera, Formicidae). Insect Soc 31: 345-360.

Slobodchikoff CN, Daly HV (1971). Systematic and evolutionary implications of parthenogenesis in the Hymenoptera. Am Zool 11: 273-282.

Smith RH, Shaw MR (1980). Haplodiploid sex ratios and the mutation rate. Nature 287: 728-729.

Suomalainen E, Saura A, Lokki J (1987). Cytology and Evolution in Parthenogenesis. CRC Press Inc.: Boca Raton, FL.

Tsuji K, Yamauchi K (1995). Production of females by parthenogenesis in the ant Cerapachys biroi. Insect Soc 42: 333-336.

Verma S, Ruttner F (1983). Cytological analysis of thelytokous parthenogenesis in the Cape honeybee (Apis mellifera capensis Escholtz). Apidologie 14: 47-58.

Waller DM (1993). The statics and dynamics of mating system evolution. In: Thornhill NW (eds) The Natural History of Inbreeding and Outbreeding: Theoretical and Empirical Perspectives. University of Chicago Press: Chicago, IL.

Werren JH (1993). The evolution of inbreeding in haplodiploid organisms. In: Thornhill NW (eds) The Natural History of Inbreeding and Outbreeding: Theoretical and Empirical Perspectives. University of Chicago Press: Chicago, IL.

White M (1984). Chromosomal mechanisms in animal reproduction. Bull Zool 51: 1-23. 